\title{
The Application of Composite Indicators to Disaster Resilience: A Case Study in Osaka Prefecture, Japan
}

\author{
Maiko Ebisudani ${ }^{1} \&$ Akihiro Tokai ${ }^{1}$ \\ ${ }^{1}$ Laboratory of Environmental Management, Division of Sustainable Energy and Environmental Engineering, \\ Graduate School of Engineering, Osaka University, Osaka, Japan \\ Correspondence: Maiko Ebisudani, Laboratory of Environmental Management, Division of Sustainable Energy \\ and Environmental Engineering, Graduate School of Engineering, Osaka University, 2-1 Yamada-oka, Suita \\ City, Osaka Prefecture 565-0871, Japan. Tel: 81-6-6105-5828. E-mail: ebisudani@em.see.eng.osaka-u.ac.jp
}

Received: November 7, 2016 Accepted: November 17, 2016 Online Published: February 3, 2017

doi:10.5539/jsd.v10n1p81 URL: http://dx.doi.org/10.5539/jsd.v10n1p81

\begin{abstract}
This paper presents an empirical verification of the measurement of baseline characteristics for fostering regional resilience. A set of indicators was selected from previous studies of disaster resilience, and an environmental element was added. The aims of the study were (1) to select a set of indicators that could be used for measuring disaster resilience, based on a review of the research literature, (2) to evaluate these indicators using the statistical approach of standardization, and to visualize the results using Geographic Information System (GIS) technology, and (3) to identify the key resilience characteristics using principal component analysis (PCA). The study focused on 29 municipalities in Osaka Prefecture, Japan. From the literature review, a total of 17 disaster resilience indicators were selected, covering economic, social, and community connection factors. The novel environmental attributes were selected from the literature on environmental sustainability. The standardized measures demonstrated that municipalities with a high level of resilience were also ranked highly on both the "social" and "community connection" attributes. The GIS mapping resulted a prominent urban-suburban divide, with urban areas having a lower level of resilience than suburban areas. The PCA demonstrated significant variation across the 29 municipalities, characterized by the factors "living standard" and "regional involvement." An understanding of these baseline characteristics would allow governments to monitor chronological changes in the resilience of specific regions. This information can be used to support the establishment of an evaluation platform, and can contribute to a more systematic management of resilience.
\end{abstract}

Keywords: disaster resilience, GIS, indicators, Japan, sustainability

\section{Introduction}

There is enormous national interest in disaster resilience as an approach to the mitigation of external stresses placed on a community (Cutter, Burton, \& Emrich, 2010). A recent disaster, the Great Eastern Japan earthquake of March 2011, increased the motivation to reconsider risk management (Ministry of the Environment, Government of Japan, 2016). This disaster caused damage that exceeded national expectations, and accentuated the need for an improved understanding of system resilience. To support the creation of a stronger and more flexible country, Japan enacted the 2013 "Basic Act for National Resilience Contributing to Preventing and Mitigating Disasters for Developing Resilience in the Lives of the Citizenry (BANR)." This placed the responsibility for measuring national resilience in a comprehensive and systematic manner on the national government (BANR, 2013). Even before the BANR, many studies had attempted to measure resilience. For example, United Nations International Strategy for Disaster Reduction (2007) provided guidelines on measuring the reduction in disaster risks and the implementation of the Hyogo framework for community-based organizations and local and national authorities. Similarly, Renschler et al. (2010) introduced the PEOPLES resilience framework for defining and measuring resilience at the community level, and Miles and Chang (2011) developed ResiUS as a community-based disaster resilience model, mainly for use following earthquakes. However, resilience is still at a conceptual stage, particularly in understanding ways of addressing external stresses, and there is a need to move from a purely theoretical understanding to actual applications in real-world settings.

In general, there are two major approaches to resilience assessment: qualitative and quantitative (Hosseini, 
Barker, \& Ramirez-Marquez, 2016). Hosseini et al. (2016) classified measurements of the resilience of systems that did not use numerical descriptors as qualitative assessments, and quantitative approaches as those that attempt to quantify resilience across different applications and modeling techniques. One of the quantitative methods entails the identification of core indicators of resilience. Cutter et al. (2010) argued that, while such indicators are widespread across the literature, no specific set of indicators has yet been established for the quantification of disaster resilience. There is a consensus that resilience is multifaceted (Cutter et al., 2010; Gunderson, 2009; National Research Council [NRC], 2010; Norris et al., 2008). However, until now, ecological elements have been excluded, due to the inconsistency of the data and doubts about their relevance (Cutter et al., 2010). The present study was designed to contribute to the quantitative approach by inclusion of an environmental dimension, and by exploring empirical applications of this more holistic set of indicators to a real-world context. A set of indicators was used to measure the conditions that affect current disaster resilience within a region, in order to establish a baseline for the characteristics that foster regional resilience. Cutter (2016) discussed a range of domain areas in disaster resilience, each of which involves different scientific variables. The present study undertook a critical examination of existing approaches to quantifying the economic, social, community connection, and environmental attributes. Since there is no single solution for resilience measurement involving the properties of environments (e.g., natural resources, ecosystems), this study adopted the central concept of "ecological resilience" for the selection of indicators of environmental attributes. We applied our methodology to Osaka Prefecture, Japan, as a proof of concept. Composite indicators are increasingly recognized as useful tools in policy-making and public communication (Cutter et al., 2010). The findings of this study can therefore contribute to a more organized process of data collection, and help to establish an evaluation platform to allow a more systematized management of resilience.

The specific objectives of this study were (1) to select a set of indicators that could be used for measuring disaster resilience, based on a review of the research literature, (2) to evaluate these indicators using the statistical approach of standardization, and to visualize the results using Geographic Information System (GIS) technology, and (3) to identify the key resilience characteristics using principal component analysis (PCA). The study was customized for the metropolitan areas in Osaka Prefecture; 29 municipalities were selected based on the availability of data.

\section{Materials and Methods}

\subsection{Literature Review}

The Web of Science database was used to identify existing provincial indicators, since it is recognized as the most comprehensive multidisciplinary search domain for use by academic researchers. Journal papers were filtered by keywords, such as disaster resilience and indicators. Both the abstracts and the full texts of the selected papers were reviewed to rank indicators. The selected indicators were then classified using a globally recognized standard. For the classification, we applied a measurement framework based on a review of documents from international authorities, including UNDP, UNISDR, and UNEP.

\subsection{Standardized Scoring and Visualization}

The selection of indicators was followed by the calculation of a standardized score and visualization of the results using GIS technology. Input data was collected for each of the 29 municipalities, and supplemented by data from the Population Census of Japan, e-Stat of the Statistics Bureau, and the Osaka Statistical Yearbook. Since the indicators are presented in a variety of units, such as percentages or monetary values (the Japanese Yen), they had to be normalized before being summed and aggregated to produce the composite indicators. This study applied the $\mathrm{z}$ score method to normalize the indicators, as this is one of the most widely used methods (Yoon \& Kang, 2013). The $\mathrm{z}$ score was calculated as follows, where $x_{i}$ represents the raw value, $\mu$ the mean value, and $\sigma$ the standard deviation.

$$
Z \text { score }=\frac{x_{i}-\mu}{\sigma}
$$

The indicators of each attribute $A_{i}$ were then given an average score using the following equation, where $N$ is the number of indicators for each attribute.

$$
A_{i}=\frac{\sum_{i=1}^{N} Z}{N}
$$

These data sets were transferred to the GIS technology to obtain a comparative overview and to visualize the spatial distribution. The average scores were restructured to allow GIS formatting and input to ArcMap 10.2.2. 


\subsection{Identification of Resilience Characteristics}

The $\mathrm{z}$ scores were analyzed using PCA, as this is an effective tool for identifying key characteristics and highlighting similarities and differences in a dataset. Statistical analysis was conducted using SPSS, Version 22 (IBM).

\section{Results and Discussion}

\subsection{Selection of Indicators}

The literature review was conducted to search for studies that provide a broad review of assessment approaches to holistic community resilience, and which specialized in examining a set of dimensions and indicators. The seven articles were identified, published between 2010 and 2016. These were from the field of water resources, the environmental sciences of ecology, and the atmospheric sciences. From these articles, studies that had developed indicators for the measurement of disaster resilience specific to regional communities were selected. This produced a total of six studies: Baseline Resilience Indicators for Communities (Cutter, Burton, \& Emrich, 2010), Community Disaster Resilience Index (Peacock et al., 2010), Community Resilience Index (Sherrieb, Norris, \& Galea, 2010), FAO Livelihoods (Alinovi, Errico, Mane, \& Romano, 2010), Oxfam GB (Hughes \& Bushell, 2013), and Resilience Capacity Index (Pendall, Foster, \& Cowell, 2010).

Based on a review of documentation from international authorities, the United Nations Development Programme (2014) derived disaster resilience measurements and classified the maturity of the measurements into six phases (Table 1), ranging from conceptual frameworks that had yet to define indicators (phase 1), to models which had developed institutionalized disaster resilience measurements and were regularly collecting data (phase 6) (UNDP, 2014). The present study used the most mature measurements. The Resilience Capacity Index (RCI) was categorized as being at phase 5 , since the data collection underpinning the indicators was systematized and the data was collected frequently. Among the measurement systems identified, we ranked RCI as one of the most mature. Additionally, as RCI covered 361 U.S. metropolitan areas, the dataset is suitable for use in comparative studies. RCI covered regional economic capacity, socio-demographic capacity, and community connectivity capacity. Each attribute used four indicators for assessment (Table 2). One indicator, health-insured, was excluded as Japan has universal health insurance.

Table 1. The development of measurement frameworks for disaster resilience (UNDP, 2014)

\begin{tabular}{lll}
\hline Least & Phase 1 & A theoretical framework for measuring resilience exists, but no indicators are yet defined. \\
\cline { 2 - 3 } Phase 2 & $\begin{array}{l}\text { A theoretical framework for measuring resilience exists, and at least some potential } \\
\text { indicators are suggested. }\end{array}$ \\
\hline Phase 3 & $\begin{array}{l}\text { A clear indicator framework based on a theoretical framework has been defined, but data } \\
\text { is not collected systematically. }\end{array}$ \\
\hline Phase 4 & As above, but some data, or data from a limited geographical area, has been collected. \\
\hline Phase 5 & As above, but the data collection is institutionalized and data is collected regularly. \\
\hline Post & Thase 6 measurement method has been empirical verified. \\
\hline
\end{tabular}

The same studies included a set of sustainability indicators, which have also been used to produce an aggregate measurement of disaster resilience. Six measurements were found, such as Human Development Index (UNDP, 1990; 2005), Environmental Sustainability Index (Esty, Levy, Srebotnjak, \& Sherbinin, 2005), Environmental Vulnerability Index (Kaly, Pratt, \& Mitchell, 2004), Human Vulnerability of Coastal Communities (Heinz Center, 2008), Ecological Indicators for the Nation (NRC, 2000), and Environmental Indicators (Organization for Economic Co-operation and Development [OECD], 2001). These measurements were used for assessing quality of life and sustainable development, which evaluate the vulnerability of the natural environment and environmental sustainability. To select the candidate indicators for the "environmental attributes" in the current study, we reviewed all of these measurements, and identified those which we considered most closely related to the concept of ecological resilience.

To understand ecological resilience, this study adopted the concept of Holling, who originally defined the term. Holling (1996) described the central concept of ecological resilience as the capacity to maintain the existence of 
a function. While ecosystems do not have a single state of equilibrium, function, and movement between states maintains both structure and diversity, which is desirable. For this reason, ecological resilience focuses on persistence and robustness against disturbance. It is measured by the magnitude of disturbance that can be absorbed before the system shifts its structure (Gunderson, Holling, Pritchard, \& Peterson, 2002). Based on this understanding, leading indicators to measure the magnitude of human disturbances of the environment were selected as possible candidates. Six indicators from the Environmental Sustainability Index (ESI) were used to assess anthropogenic stresses from air pollution, ecosystem stress, population pressure, waste and consumption, water stress, and natural resource management. Each indicator comprised several variables. Significant variables were selected for each indicator, taking account of data availability. Table 2 shows the final set of indicators used in the study. Variables were measured to confirm that a high value was associated with a greater resilience.

Table 2. The final set of designated indicators

\begin{tabular}{|c|c|c|}
\hline Attribute & Indicator & Variable \\
\hline \multirow[t]{4}{*}{ Economic (EA) } & Income Equality & Inverse of Gini coefficient ( 0 : perfect equality). \\
\hline & $\begin{array}{l}\text { Economic } \\
\text { diversification }\end{array}$ & $\begin{array}{l}\text { Inverse of sum of differences of the metropolitan economy from } \\
\text { the national economy by the proportion of jobs in goods, } \\
\text { services, and the government sector (1- sum of differences). }\end{array}$ \\
\hline & $\begin{array}{l}\text { Regional } \\
\text { affordability }\end{array}$ & $\begin{array}{l}\text { A measurement of economic security based on the percentage of } \\
\text { a metropolitan area's households that spend less than } 35 \text { percent } \\
\text { of their income on housing. }\end{array}$ \\
\hline & $\begin{array}{l}\text { Business } \\
\text { Environment }\end{array}$ & $\begin{array}{l}\text { A disproportionately high level of small and large businesses and } \\
\text { high levels of business churn (starts and stops). }\end{array}$ \\
\hline \multirow[t]{3}{*}{$\begin{array}{l}\text { Socio-demographic } \\
\text { (SA) }\end{array}$} & $\begin{array}{l}\text { Educational } \\
\text { attainment }\end{array}$ & $\begin{array}{l}\text { The percentage of the population aged } 25+\text { with a bachelor's } \\
\text { degree or higher, divided by the percentage of the population } \\
\text { aged } 25+\text { without a high school diploma or GED. }\end{array}$ \\
\hline & Without disability & Inverse percentage of holders of a disability certificate. \\
\hline & Out of poverty & $\begin{array}{l}\text { Inverse of poverty: the percentage of the population whose } \\
\text { income over the past } 12 \text { months was above the federally defined } \\
\text { poverty line ( } 3 \text { million yen/year). }\end{array}$ \\
\hline \multirow[t]{4}{*}{$\begin{array}{l}\text { Community } \\
\text { connection (CA) }\end{array}$} & Civic infrastructure & $\begin{array}{l}\text { Number of civic organizations per } 10,000 \text { population, such as } \\
\text { labor unions, political groups, social education institutions, social } \\
\text { welfare corporations, voluntary centers, membership of volunteer } \\
\text { hospital associations. }\end{array}$ \\
\hline & $\begin{array}{l}\text { Metropolitan } \\
\text { stability }\end{array}$ & $\begin{array}{l}\text { Average annual percentage over a five-year period of the } \\
\text { population who lived within the same metropolitan area a year } \\
\text { earlier. }\end{array}$ \\
\hline & Homeownership & $\begin{array}{l}\text { Number of owner-occupied housing units as a percentage of total } \\
\text { occupied housing units. }\end{array}$ \\
\hline & Voter participation & Voting rate. \\
\hline \multirow[t]{6}{*}{ Environment (EVA) } & Air pollution & Inverse of vehicles in use against area of populated land. \\
\hline & Ecosystem Stress & Annual average rate of change of forest cover from 2001 to 2014 . \\
\hline & Population Pressure & $\begin{array}{l}\text { Inverse of the percentage change in projected population } \\
2015-2040\end{array}$ \\
\hline & $\begin{array}{l}\text { Waste \& } \\
\text { consumption } \\
\text { pressures }\end{array}$ & Waste recycling rate. \\
\hline & Water stress & $\begin{array}{l}\text { Inverse of the sum of industrial organic water pollution (BOD) } \\
\text { emissions against available freshwater. }\end{array}$ \\
\hline & $\begin{array}{l}\text { Natural resource } \\
\text { management }\end{array}$ & $\begin{array}{l}\text { Percentage of total forest area that is certified as under } \\
\text { sustainable management. }\end{array}$ \\
\hline
\end{tabular}


This list was compared with existing indicators from the reviewed articles and those most often used in disaster resilience case studies were retained, while specific indicators related to environmental attributes were introduced. Cutter (2016) examined indicators of community resilience in the USA and identified ten distinct variables that appeared in more than $40 \%$ of the empirical studies of resilience. The specific variables that appeared in multiple studies were social indicators and social capital, related to civic organizations, health care access, and religious affiliation. Income and educational inequality were also used in half the studies (Cutter, 2016). In contrast, no consensus emerged on the measurement of environmental capital. The present study therefore applied an original conceptualization of ecological resilience. The environmental indicators selected were previously used in global-level assessment, and needed to be localized to the community level.

\subsection{Assessing Disaster Resilience in Osaka}

The seventeen indicators listed in Table 2 were used to evaluate the disaster resilience of the 29 municipalities in Osaka Prefecture.

\subsubsection{Disaster Resilience Scores (DRS)}

Each indicator was calculated following the direction described under "variable" in Table 2, taken from Foster (2012). Economic attributes capture aspects of regional industrial structure and the economic resources of the population; in this case, the higher the diversity, the greater the resilience. Socio-demographic attributes gauge how effectively the community members respond to a disturbance mentally, physically, or materially. Community connection attributes measure the extent to which individuals within a region are familiar with and loyal to that region. The newly-added environmental attributes capture the degree of human disturbance to the natural environment. Each variable was standardized as a z score and the mean scores are shown in Table 3.

Table 3. Municipalities with highest and lowest disaster resilience scores (DRS)

\begin{tabular}{clccccc}
\hline \multicolumn{1}{c}{ Rank } & Name & EA & SA & CA & EVA & DRS \\
\hline Most DRS & Minoh-shi & -0.77 & 2.11 & 0.66 & 0.47 & 0.62 \\
\hline 1 & Ibaraki-shi & 0.18 & 0.97 & 0.82 & -0.03 & 0.48 \\
3 & Ikeda-shi & 0.01 & 1.12 & 0.34 & 0.12 & 0.40 \\
4 & Suita-shi & 0.06 & 0.53 & 0.76 & 0.11 & 0.36 \\
5 & Takatsuki-shi & -0.28 & 0.71 & 0.87 & 0.11 & 0.35 \\
6 & Kawachinagano-shi & -0.91 & 1.13 & -0.18 & 1.28 & 0.33 \\
7 & Settsu-shi & 0.20 & 0.27 & 0.96 & -0.13 & 0.32 \\
8 & Kashiwara-shi & 0.96 & 0.28 & -0.44 & 0.11 & 0.23 \\
9 & Toyonaka-shi & 0.02 & 0.85 & 0.13 & -0.15 & 0.21 \\
10 & Hirakata-shi & -0.08 & 0.43 & 0.24 & 0.22 & 0.20 \\
\hline Least DRS & & & & & & \\
1 & Kadoma-shi & 0.23 & -1.48 & -0.93 & 0.00 & -0.55 \\
2 & Matsubara-shi & -0.29 & -0.97 & -0.40 & 0.14 & -0.38 \\
3 & Habikino-shi & -0.49 & -0.10 & -0.38 & -0.42 & -0.35 \\
4 & Sennan-shi & -0.33 & -0.90 & 0.05 & -0.13 & -0.33 \\
5 & Higashiosaka-shi & 1.00 & -1.36 & -0.68 & -0.27 & -0.33 \\
6 & Kishiwada-shi & -0.03 & -0.64 & -0.64 & 0.16 & -0.29 \\
7 & Osaka-shi & 0.23 & -1.46 & 0.13 & -0.04 & -0.29 \\
8 & Kaizuka-shi & 0.31 & -0.92 & 0.05 & -0.43 & -0.25 \\
9 & Moriguchi-shi & 0.15 & -1.03 & -0.51 & 0.46 & -0.23 \\
10 & Izumisano-shi & 0.48 & -0.73 & -0.24 & -0.28 & -0.19 \\
\hline
\end{tabular}


The disaster resilience score (DRS) gave the average $\mathrm{z}$ score of each attribute after equally weighting the variables. The reason for applying equal weighting in the present study is due to the equal importance and effectiveness of recovery measures in disaster management. Each attribute was calculated as the average of the $\mathrm{z}$ score values for each variable within that attribute: four for regional economic resilience, three for socio-demographic resilience, four for community connection resilience, and six for environmental resilience. From this analysis, Minoh-shi was ranked highest, with an average score of 0.62 , followed by Ibaraki-shi, Ikeda-shi, Suita-shi, and Takatsuki-shi. All the top five achieved a high ranking on the strength of their socio-demographic capacity and community connection capacity, both of which tend to be high in residential areas with good neighborhoods. However, the same regions have comparatively lower resilience in terms of regional economic capacity. Metropolitan areas with relatively low resilience capacity - led by Higashiosaka-shi - were consistently low across all four attributes.

The results were compared with existing studies which had applied RCI in U.S. metropolitan areas. As explained in Section 3.1, RCI used only three attributes: regional economic capacity, socio-demographic capacity, and community connection capacity. We therefore compared the findings on these three dimensions. Based on the population size, total GDP, and GDP per capita (Cabinet Secretariat, 2009), Michigan State was found to be similar to Osaka prefecture. For comparison, the average z scores for 14 municipalities in Michigan State (Building Resilient Regions, 2011) were used. The highest-ranked metropolitan area was Holland, with an average score of 0.62, followed by Bay City, Monroe, Grand Rapids, and Ann Arbor. Each achieved a high ranking on socio-demographic capacity and community connectivity capacity, mirroring the pattern found in Osaka prefecture. This suggested that a high level of resilience tends to be associated with a high ranking in both socio-demographic capacity and community connectivity capacity.

As a further comparison, an assessment framework developed by the Japan Sustainable Building Consortium (JSBC) to evaluate overall regional sustainability including environmental performance was used. This considered the maintenance of city functions (economic and social activities) while moving towards a low-carbon society (JSBC, 2013). This evaluation tool is known as the Comprehensive Assessment System for Built Environment Efficiency (CASBEE), and comprises three attributes - economic, social, and environmental - producing an assessment of the level of regional environmental efficiency as a final score. Baba and Tanaka (2015) described the CASBEE as an example of resilience assessment, based on interviews with local policy makers and government workers in the National Resilience Promotion Office, Cabinet Secretariat of Japan, and Ministry of the Environment, Japan. The present study compared the measurement framework and the results.

JSBC (2013) described CASBEE as having either five or eleven variables for each attribute: five variables in economic attributes, eleven variables in social attributes, and five variables in environmental attributes. These variables were calculated as the quality of the environment (Q). In addition, greenhouse gas emissions ( $\mathrm{t}-\mathrm{CO}_{2} /$ person) were used to calculate the environmental load (L). Environmental efficiency (BEE: Built Environment Efficiency) was calculated from scores on the quality of the environment (Q) and environmental load (L): Q/L. Regions which ranks higher in quality and lower in load is assumed to have a greater level of environmental efficiency. Applying the BEE to the 29 Osaka municipalities gave Ibaraki-shi, Kawachinagano-shi, and Minoh-shi the highest scores. They achieved the highest scores on quality of environment, while the environmental load scores were lower.

Both DRS and CASBEE demonstrate the importance of environmental attributes in fully understanding regional sustainability. Similar indicators and variables were used to measure environmental attributes in the two frameworks, and both demonstrated the extent of anthropogenic environmental stress. In both frameworks, the environmental attributes included air pollution, forest coverage, waste recycling rates, and water pollution. In contrast, they used different variables to derive economic and social attributes. CASBEE was more concerned with policy and public service evaluation, for example by quantifying public facilities such as hospitals, libraries, and nursing homes, the workforce, gross regional product (GRP), and local tax revenues. As it takes policy as a framework, CASBEE is more focused on structure rather than capacity. Conversely, the DRS indicators focus on capacity measurement, with the aim of testing the regional capacity to recover from a potential stress.

Despite these differences, both approaches gave Ibaraki-shi, Kawachinagano-shi, and Minoh-shi overall high scores, and specifically for their environmental attributes. From the perspective of resilience, DRS suggested that Kawachinagano-shi has low capacity in economic security, especially in "economic diversification." This city has a narrower economic base and thus lower economic security, identifying a potential vulnerability in its regional economy. To strengthen the resilience of the region, countermeasures to diversify the industrial structure and reduce the burden of housing are required. The area has a low capacity in "community connection," and especially in "metropolitan stability." This reflects the number of residents who are potentially isolated, or 
unfamiliar with the region. To increase resilience in this area, a networking system could be established to help individuals integrate into the neighborhood and community.

To further elucidate patterns of resilience capacity, future research will analyze data from different municipalities in Japan. Additionally, the weighting applied to each of the variables should be developed further in order to adopt a more pragmatic framework. This improvement could be made by making use of historical data to identify effective recovery measures following disasters. Further development should apply the combination of sensitivity analysis to validate output. OECD (2008) has proposed how to design, develop, and disseminate a set of composite indicators. Sensitivity analysis was stated as one of the techniques to improve the complexity of composite indicators. The validation helps to improve the quality of composite indicators and identify effective sensitivity indices.

\subsubsection{Visualization}

The study investigated the use of spatial visualization to identify regions that require greater disaster resilience. The DRS calculated for each of the municipalities was transferred to GIS formatting and input into ArcMap 10.2.2. Figure 1 shows disaster resilience within the study area.

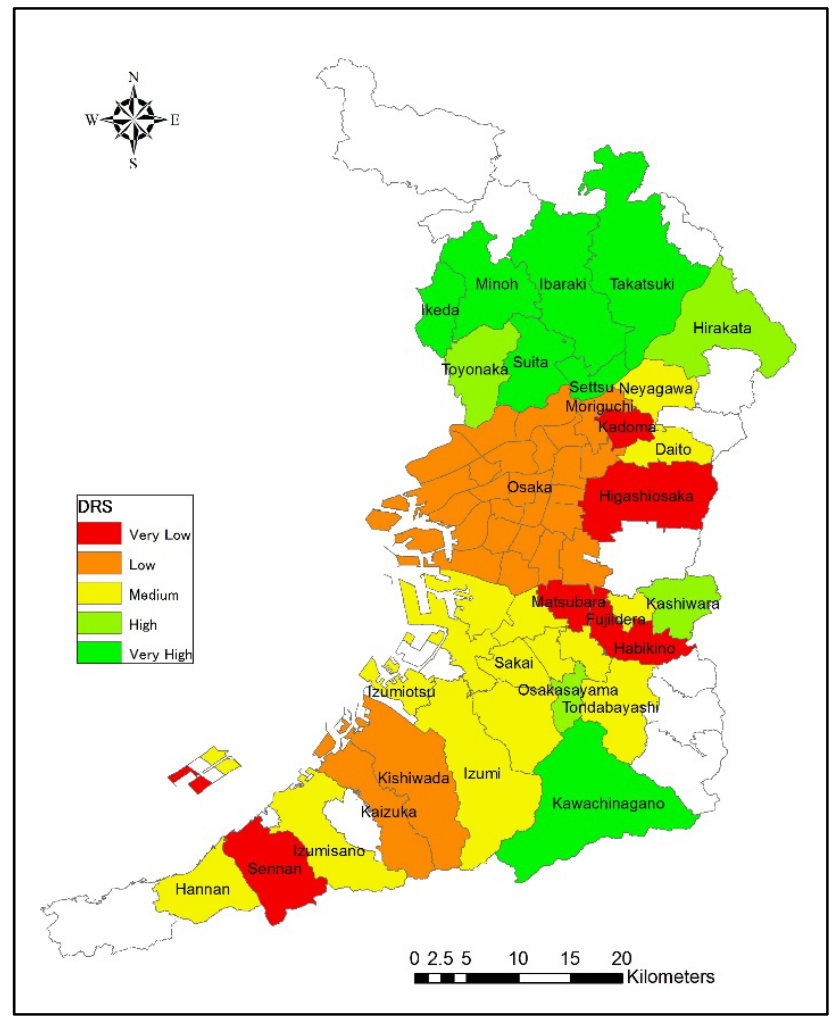

Figure 1. Spatial distribution pattern of DRS

Our DRS scores were clustered into five categories: Very High $(>0.24)$, High $(0.03 \sim 0.23)$, Medium $(-0.22 \sim$ $0.02)$, Low $(-0.32 \sim-0.23)$, and Very Low $(<-0.33)$. Municipalities shown in bright green are highly resilient, whereas municipalities shown in red have comparatively low resilience. When visualized as a regional map, geographic variations become more apparent. The results highlight an urban-rural bias, with urban areas such as Osaka, Higashiosaka, and Sakai having a comparatively low level of resilience, while suburbs such as Minho, Ibaraki, and Suita are more highly resilient. A north-south bias can also be observed, with a high level of resilience north of Osaka-shi, while southern areas typically exhibit medium to low levels of resilience.

The ranking produced by our measures matched what is known about the different regions of Osaka prefecture. For example, Osaka Prefectural Government (2006) characterized the suburban region bordering the north side of Osaka-shi as being notable for its unique landscape resources, having a combination of plains and hilly areas. This area has green spaces facilities (e.g., Expo Park and Parkland) and is known as a comfortable residential environment. Our measures provided comparable results, ranking this region relatively highly in DRS (Figure 1). The study examined geographic variation, and identified patterns within the limited area of the study. However, 
the score is highly dependent on the variables and indicators selected. To expand these results, the same data could be accumulated to allow comparisons between different regions, helping to reveal patterns of resilience.

\subsection{Characterization of Disaster Resilience}

The $\mathrm{z}$ scores calculated for each variable were transferred to the statistical analysis software SPSS for PCA.

Table 4 shows the results.

Table 4. Result from principal components analysis (PCA)

\begin{tabular}{|c|c|c|}
\hline Variable & Factor 1 & Factor 2 \\
\hline SA_Educational Attainment & 0.822 & 0.316 \\
\hline SA_Out of Poverty & 0.753 & -0.236 \\
\hline SA_Without Disability & 0.751 & 0.076 \\
\hline CA_Voter Participation & 0.743 & 0.126 \\
\hline EVA_Reducing Water Stress & 0.652 & 0.121 \\
\hline CA_Homeownership & 0.596 & -0.393 \\
\hline EVA_Reducing Waste \& Consumption Pressures & 0.516 & -0.238 \\
\hline CA_Metropolitan Stability & 0.363 & 0.758 \\
\hline EVA_Natural Resource Management & 0.304 & -0.349 \\
\hline EA_Business Environment & 0.143 & 0.591 \\
\hline EVA_Reducing Ecosystem Stress & -0.074 & 0.076 \\
\hline EVA_Reducing Population Pressure & -0.213 & -0.354 \\
\hline EVA_Reducing Air Pollution & -0.302 & 0.462 \\
\hline EA_Regional Affordability & -0.349 & 0.749 \\
\hline EA_Income Equality & -0.362 & -0.615 \\
\hline CA_Civic Infrastructure & -0.505 & 0.419 \\
\hline EA_Economic Diversification & -0.565 & -0.198 \\
\hline
\end{tabular}

The PCA identified three primary characteristics in the first factor: educational attainment (with or without a higher school diploma), poverty (over or under the poverty line) and disability (with or without a disability certificate). Considering the nature of these characteristics, this factor was labeled "living standard." The second factor primarily reflected the three characteristics of metropolitan stability (living within same area over a five-year period or less), regional affordability (spending less or more than 35 percent of income on housing), and business environment (degree of business diversity). These characteristics gave this factor the label "regional involvement." These scores give the location of each municipality within the factor space, and Figure 2 plots these for Factors 1 and 2. Municipalities ranked low on the horizontal dimension (Factor 1) were identified as having limited educational, economic, and health resources. These municipalities, such as Osaka-shi, must provide special care for the people who face these difficulties and educate them to increase their disaster awareness. Municipalities ranked low on Factor 2 have less "regional involvement," notably Kawachinagano-shi. The main characteristics of this dimension are a lack of business diversity and lower economic security. It also indicates the risk of residents being isolated, as discussed in Section 3.2.1. Higashiosaka-shi, with negative ratings on Factor 1 and 2, requires countermeasures against both.

The results suggest that measures to foster regional resilience are related to factors such as the living standard and regional involvement. These two factors should be considered when designing resilience management strategies. They provide baseline characteristics for the regional resilience to natural disasters. Municipalities that fall at the negative end on both factors can be considered most critically in need of appropriate countermeasures, as part of a regional strategy for surviving potential disasters. 
Regional involvement

Factor 2

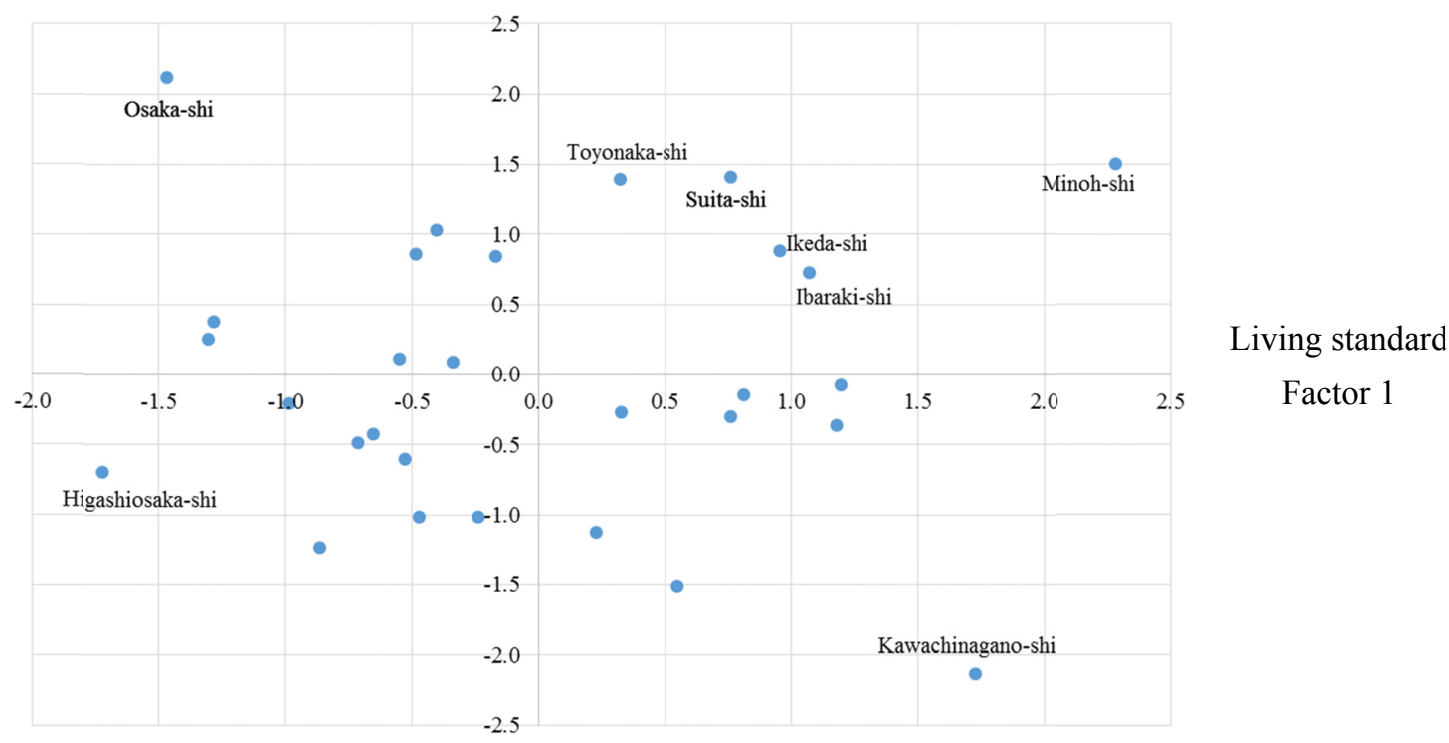

Figure 2. Location of 29 municipalities on Factor 1 and 2

\section{Conclusions}

Based on a review of existing indicators, this study proposed a holistic set of variables for the measurement of disaster resilience. These variables include those most often used in previous case studies on disaster resilience. We also introduced a novel environmental attribute element, to reflect the original concept of ecological resilience. Using standardization and PCA statistical techniques, the study confirmed that this set of indicators could be used to establish the baseline characteristics of disaster resilience. The study comprised three phases, the findings of each were as follows:

(1) A set of indicators was selected from a combination of disaster resilience and environmental elements. In the selection process, existing indicator frameworks were reviewed and ranked by reference to their maturity. Candidate indicators for use as environmental attributes were selected to develop the concept of ecological resilience. Seventeen indicators were identified as the final set.

(2) DRS results were standardized, fed into GIS technology, and compared with results from Michigan State and CASBEE. The results confirmed that DRS was an effective approach to testing the regional capacity to recover from a potential stress. The 29 municipalities in Osaka prefecture were used to test this approach, and the mean scores for disaster resilience suggested that a municipality with a high level of resilience tends to also have a high socio-demographic capacity and community connectivity. Michigan State showed a similar pattern to Osaka Prefecture. Comparison of the results with those from CASBEE showed CASBEE to be more focused on structure, while the DRS indicators are focused on capacity measurement. In the case study, the DRS data was transferred to GIS formatting and the geological variation visualized. The results highlighted an urban-suburban split, with urban areas having a lower level of resilience than suburban areas. A north-south bias was also identified, with areas north of Osaka-shi having a high level of resilience, while southern areas typically showed medium to low resilience. This was consistent with the known geographic variations and patterns of Osaka prefecture. DRS was shown to be valuable for use in comparative assessment, providing a classification process that helps understand the resilient of a given region, and compare it with other regions. This can provide knowledge to local policy makers, informing the decision-making process.

(3) To establish baseline characteristics for resilience capacity, PCA was applied and the municipalities were characterized on two dimensions: "living standard" and "regional involvement." These are the two key factors that should be considered when planning resilience management. A municipality that falls at the negative end of both factors is most critically in need of appropriate countermeasures, and these should form 
part of a regional strategy. The analysis suggested specific countermeasures to be applied in Osaka-shi, Kawachinagano-shi, and Higashiosaka-shi. Overall, the results confirm the necessity of developing regional preparedness for disasters.

Our study further supports the argument that resilience indicators can be used to identify patterns and to capture the overall characteristics of resilience in a region. This can help establish an evaluation platform, and contribute to a more systematized management of resilience.

For future development, the combination of weight analysis and sensitivity analysis can help to validate the result, and the same process of verification must be applied in different municipalities. The compilation of a series of datasets will improve the accuracy of the information available, and provide a useful tool for decision-making.

\section{Acknowledgments}

We would like to express our gratitude to the contributors and reviewers of this paper. The study was completed with the support of the Environment Research and Technology Development Fund, Ministry of the Environment, Government of Japan (1-1304).

\section{References}

Alinovi, L., D'Errico, M., Mane, E., \& Romano, D. (2010). Livelihoods strategies and household resilience to food insecurity: an empirical analysis to Kenya. European Report on Development, FAO, Rome. Retrieved from http://erd.eui.eu/media/BackgroundPapers/Alinovi-Romano-D'Errico-Mane.pdf

Baba, K., \& Tanaka, M. (2015). A Concept of Resilient City and Providing Assessment Indicators. Journal of the City Planning Institute of Japan, 50(1), 46-53. Retrieved from https://www.jstage.jst.go.jp/article/journalcpij/50/1/50_46/_article/_char/ja/ (in Japanese)

Basic Act for National Resilience Contributing to Preventing and Mitigating Disasters for Developing Resilience in the Lives of the Citizenry. (2013). Retrieved from http://www.cas.go.jp/jp/seisaku/kokudo_kyoujinka/pdf/khou1-2.pdf (in Japanese)

Building Resilient Regions. (2011). RCI Ranking. Retrieved from http://brr.berkeley.edu/rci/data/ranking

Cabinet Secretariat. (2009). US population, land area and GDP by States. Retrieved from http://www.cas.go.jp/jp/seisaku/doushuu/kuwari/dai6/siryou3.pdf

Cutter, S. L. (2016). The landscape of disaster resilience indicators in the USA. Natural Hazards, 80(2), 741-758. http://doi.org/10.1007/s11069-015-1993-2

Cutter, S. L., Ash, K. D., \& Emrich, C. T. (2014). The geographies of community disaster resilience. Global Environmental Change, 29, 65-77. http://doi.org/10.1016/j.gloenvcha.2014.08.005

Cutter, S. L., Barnes, L., Berry, M., Burton, C., Evans, E., Tate, E., \& Webb, J. (2008). A place-based model for understanding community resilience to natural disasters. Global Environmental Change, 18(4), 598-606. http://doi.org/10.1016/j.gloenvcha.2008.07.013

Cutter, S. L., Burton, C. G., \& Emrich, C. T. (2010). Disaster Resilience Indicators for Benchmarking Baseline Conditions. Journal of Homeland Security and Emergency Management, 7(1), 14. http://doi.org/10.2202/1547-7355.1732

Esty, D. C., Levy, M., Srebotnjak, T., \& de Sherbinin, A. (2005). 2005 Environmental Sustainability Index: Benchmarking National Environmental Stewardship. New Haven: Yale Center for Environmental Law \& Policy. Retrieved from http://www.yale.edu/esi

Foster, K. A. (2012). In Search of Regional Resilience. Bookings Institution Press, New York, NY.

Gunderson, L. (2009). Comparing Ecological and Human Community Resilience. CARRI Research Report, 5. Retrieved from http://www.resilientus.org/library/Final_Gunderson_1-12-09_1231774754.pdf

Gunderson, L., Holling, C. S., Pritchard, L., \& Peterson, G. D. (2002). Resilience. In H. A. Mooney, \& J. G. Canadell (Eds.), Encyclopedia of Global Environmental Change (Vol. 2, pp. 530-531). Scientific Committee on Problems of the Environment.

Holling, C. S. (1996). Engineering resilience versus ecological resilience. In P. Schulze (Ed.), Engineering within ecological constraints (pp. 31-43). National Academy of Engineering. http://dx.doi.org/10.17226/4919

Hosseini, S., Barker, K., \& Ramirez-Marquez, J. E. (2016). A review of definitions and measures of system resilience. Reliability Engineering and System Safety, 145, 47-61. http://doi.org/10.1016/j.ress.2015.08.006 
Hughes, K., \& Bushell, H. (2013). A Multidimensional Approach for Measuring Resilience. Oxfam GB working paper, London. Retrieved from http://policy-practice.oxfam.org.uk/publications/a-multidimensional-approach-to-measuring-resilience-3026 41

Japan Sustainable Building Consortium. (2013). Comprehensive Assessment System for Built Environment Efficiency-Metropolitan areas. Retrieved from http://www.ibec.or.jp/cgi-bin/cas_city/access-blocker.cgi (in Japanese)

Miles, S. B., \& Chang, S. E. (2011). ResilUS: A Community Based Disaster Resilience Model. Cartography and Geographic Information Science, 38(1), 36-51. http://doi.org/10.1559/1523040638136

Ministry of the Environment Government of Japan. (2016). Ecosystem-based disaster risk reduction. Retrieved from http://www.env.go.jp/nature/biodic/eco-drr/pamph01.pdf

National Research Council. (2010). Private-Public Sector Collaboration to Enhance Community Disaster Resilience. Washington, DC: The National Academies Press. http://doi.org/978-0-309-15106-1

Norris, F. H., Stevens, S. P., Pfefferbaum, B., Wyche, K. F., \& Pfefferbaum, R. L. (2008). Community resilience as a metaphor, theory, set of capacities, and strategy for disaster readiness. American Journal of Community Psychology, 41(1-2), 127-150.

Organisation for Economic Co-operation and Development. (2008). Handbook on Constructing Composite Indicators: Methodology and User Guide. Methodology (Vol. 3). http://doi.org/10.1787/9789264043466-en

Osaka Prefectural Government. (2006). Grand Design of Urban Infrastructure in Kinki Region. Retrieved from http://www.mlit.go.jp/kisha/kisha06/02/020809/02.pdf

Peacock, W. G., Brody, S. D., Seitz, W. A., Merrell, W. J., Vedlitz, A., Zahran, S., ... Stickney, R. R. (2010). Advancing the resilience of coastal localities: developing, implementing and sustaining the use of coastal resilience indicators: a final report. Hazard Reduction and Recovery Center, Texas A\&M University, College Station. Retrieved from http://hrrc.arch.tamu.edu/_common/documents/10-02R.pdf

Pendall, R., Foster, K. A., \& Cowell, M. (2010). Resilience and regions: Building understanding of the metaphor. Cambridge Journal of Regions, Economy and Society, 3(1), 71-84. http://doi.org/10.1093/cjres/rsp028

Renschler, C. S., Frazier, A. E., Arendt, L. A., Cimellaro, G.-P., Reinhorn, A. M., \& Bruneau, M. (2010). A Framework for Defining and Measuring Resilience at the Community scale: The PEOPLES Resilience Framework. Technical Report MCEER-10-0006. http://doi.org/10.1016/j.engstruct.2010.08.008

Sherrieb, K., Norris, F. H., \& Galea, S. (2010). Measuring Capacities for Community Resilience. Social Indicators Research, 99(2), 227-247. http://doi.org/10.1007/s11205-010-9576-9

United Nation Development Programme. (1990). Human Development Report 1990. New York, NY: Oxford University Press. http://doi.org/0-19-506481-X

United Nation Development Programme. (2005). Human Development Report 2005. Retrieved from http://hdr.undp.org/en/media/HDR05_complete.pdf

United Nation Development Programme. (2014). Disaster resilience measurments- stocktaking of ongoing efforts in developing systems for measuring resilience. Retrieved from http://www.preventionweb.net/files/37916_disasterresiliencemeasurementsundpt.pdf

United Nations International Strategy for Disaster Reduction. (2007). Hyogo Framework for Action 2005-2015: Building the Resilience of Nations and Communities to Disasters. Geneva, Switzerland: UN/ISDR. Retrieved from http://www.unisdr.org/files/1037_hyogoframeworkforactionenglish.pdf

Yoon, D. K., \& Kang, J. (2013). A Measurement of Community Disaster Resilience in Korea. In Proceedings of International Symposium on City Planning 2013 (pp. 1-19).

\section{Copyrights}

Copyright for this article is retained by the author(s), with first publication rights granted to the journal.

This is an open-access article distributed under the terms and conditions of the Creative Commons Attribution license (http://creativecommons.org/licenses/by/4.0/). 